CASE REPORT

\title{
Alveolar adenoma of the lung: a clinicopathological description of a case of this very unusual tumour
}

\author{
A Halldorsson, S Dissanaike, K S Kaye
}

J Clin Pathol 2005;58:1211-1214. doi: 10.1136/icp.2004.020800

Alveolar adenomas are extremely rare, and are probably benign lung tumours of unknown histogenesis. This report describes a case of alveolar adenoma in a 43 year old white man, who presented with pleuritic chest pain. A chest $x$ ray and computerised tomography scan demonstrated a solitary left lower lobe lung nodule. Although a positron emission tomography scan seemed to document the benign nature of the lesion, a thoracoscopic wedge resection was performed to alleviate the symptoms and verify the diagnosis. Histologically, the lesion was well demarcated, dominated by large and small cysts with no normal lung parenchyma. The interstitial cellular component consisted of both epithelioid and vaguely spindle shaped cells. The cystic cell linings were mostly indistinct, although areas of cuboidal epithelial cells were seen. Multiple histochemical and immunohistochemical tests were performed. There were no histological signs of malignancy and the patient is doing well one and a half years postoperatively.

A lveolar adenoma is a pulmonary tumour of uncertain histogenesis. It was first described by Yousem and Hochholzer in 1986 and is sometimes referred to as "Yousem's tumour". ${ }^{1}$ The only cumulative study is an analysis of 17 cases undertaken by Burke et al in 1999. ${ }^{2}$ Full knowledge and understanding of these tumours is hampered by the fact that very few cases have been reported in the literature. Most authors agree that histologically these tumours are benign and recurrence has never been reported after resection. ${ }^{1-3}$ Some authors have suggested that alveolar adenomas of the lung may represent the benign counterpart of bronchioloalveolar carcinoma. ${ }^{4}$ Our case study adds to the current literature a patient with a full clinical evaluationincluding for the first time to our knowledge a preoperative positron emission tomography (PET) scan-the description of gross, histological, histochemical, and immunohistochemical findings, and a one and a half year follow up after resection.

\begin{abstract}
"Most authors agree that histologically these tumours are benign and recurrence has never been reported after resection"
\end{abstract}

\section{CASE REPORT}

A 43 year old otherwise healthy white man presented with complaints of left sided pleuritic chest pain of a few weeks duration. The patient was a non-smoker, but had possibly been exposed to hazardous chemicals during military service. A physical examination was unremarkable. A chest roentgenogram revealed a left lower lobe nodule approximately $1-$ $2 \mathrm{~cm}$ in diameter. A computerised tomography (CT) scan

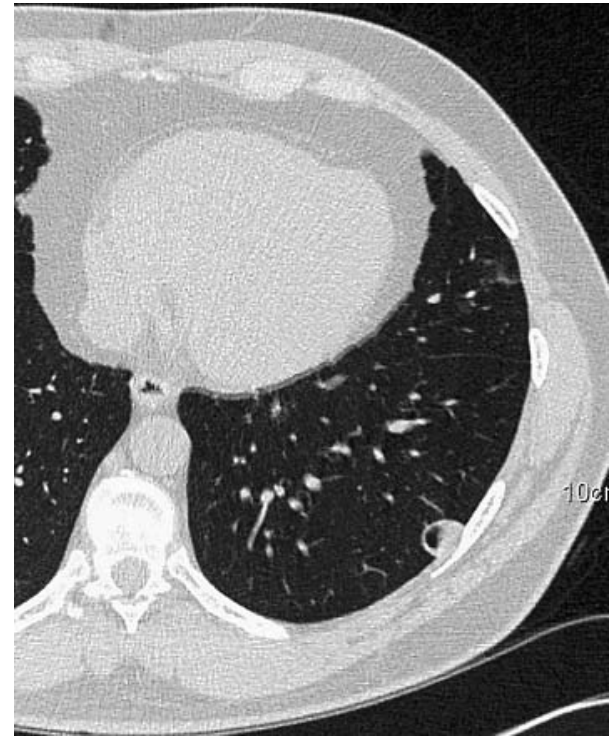

Figure 1 Computerised tomography scan of the chest showing a small posterolateral lung lesion in the lower lobe of the left lung.

verified the finding of a well circumscribed pleural based left lower lobe nodule, with no other abnormal findings (fig 1). The patient underwent a fluorine-18-flurodeoxyglucose PET scan, which showed no signs of malignant or infectious processes in relation to the nodule (fig 2). Because of the patient's continuous symptoms and concern for possible malignancy, the nodule was surgically removed. The patient underwent video assisted thorascopic surgery with a wedge resection of the nodule in the left lower lobe, lymph node sampling, and a lung biopsy. His recovery was uneventful, and 18 months later there is no sign of recurrence.

\section{PATHOLOGICAL FINDINGS}

The lung specimen showed a pleural based nodule measuring $1.1 \times 0.7 \times 0.6 \mathrm{~cm}$ in diameter. The overlying visceral pleura had whitish/tan discolouration, but otherwise showed minimal reaction. On fresh cut, the tumour was macroscopically found to be "encapsulated" with a section surface that was soft, almost gelatinous, tan, and glistening. The tumour almost shelled out from the surrounding lung parenchyma. On closer examination, the cut surface was seen to be multicystic with small focal areas of haemorrhage. Cultures were obtained and were negative for fungi and tuberculosis.

Histologically, the periphery of the tumour was reasonably well circumscribed. The most prominent features were multiple cystic spaces that appeared to become larger towards

Abbreviations: CK, cytokeratin; CT, computerised tomography; PET, positron emission tomography 


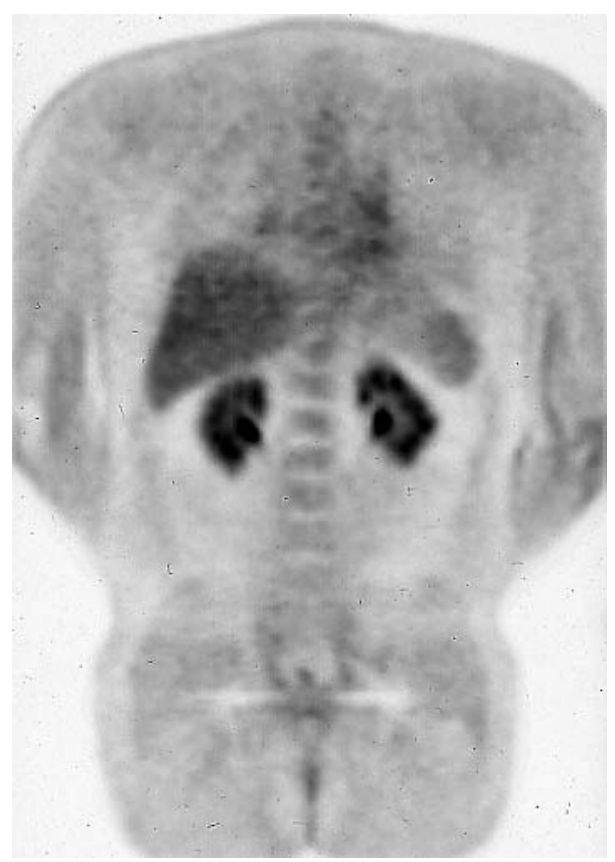

Figure 2 Coronal section from the fluorine-18-flurodeoxyglucose positron emission tomography scan through the area of the lung containing the fumour shows no isotope uptake.

the centre of the lesion (fig 3). Most of the cysts contained proteinous granular eosinophilic material, generally acellular. The cystic spaces were separated by delicate myxoid stroma and the cysts had an indistinct lining, but occasionally flattened cuboidal epithelial cells were present. The cells between the cysts were both epithelioid and vaguely spindle shaped, forming short fascicles. Many inflammatory cells were present (mainly plasma cells) and lymphoid aggregates were readily identifiable (fig 4 ).

On high magnification, a consistently high chromatin density was noted in the stromal cells and clear or vacuolated cytoplasm of the epithelial cells lining the cystic spaces. The spindle shaped cells of the stroma had a pale, bubbly, vacuolation reminiscent of the smooth muscle cells of a lymphangioleiomyomatosis. Mitoses were very rarely seen.

\section{IMMUNOHISTOCHEMICAL AND HISTOCHEMICAL FINDINGS}

The acellular material within the cystic spaces was noted to be periodic acid Schiff positive. The mucicarmine stain was negative. The cells lining the cysts were found to be positive for cytokeratin (CK) AEl/AE3, CK7, CK20, and thyroid transcription factor 1 (fig 5). The stromal cells were negative for these markers.

\section{DISCUSSION}

Alveolar adenomas are extremely rare pulmonary neoplasms. The exact number of reported cases is difficult to ascertain because these tumours are often confused with other rare lung tumours. Using strict criteria of histology, histochemistry, and immunohistochemical studies, as defined by Burke et al in 1999, less than 25 cases of true alveolar adenoma have been reported. ${ }^{1-14}$

These tumours have been reported in all major geographical areas of the world and have been found in all races. ${ }^{1-14}$ Most patients are middle aged to elderly, with a slight female predominance. These tumours are most often an incidental finding on a radiological examination, and when symptoms have been reported, they are either unrelated to the lesion or

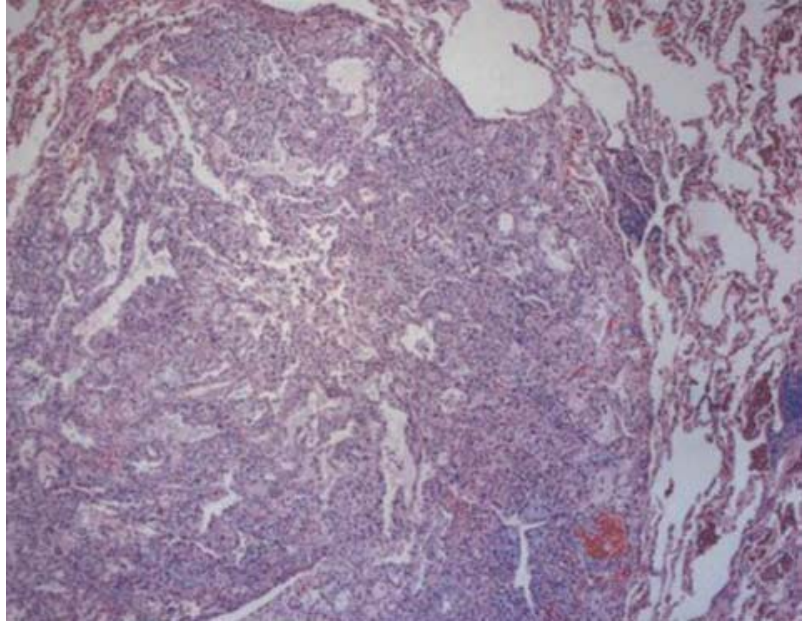

Figure 3 The tumour is well circumscribed and multicystic (haematoxylin and eosin stain; original magnification, $\times 40$ ).

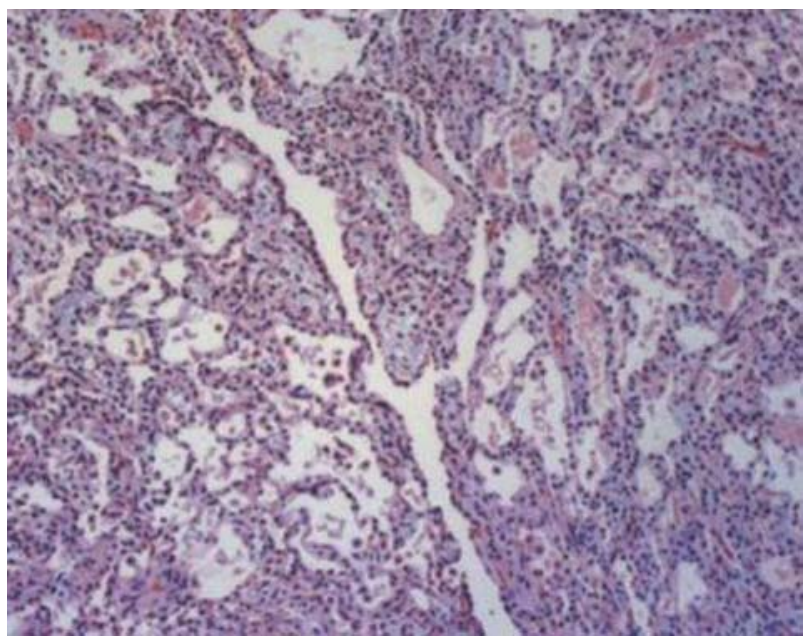

Figure 4 The variably sized cystic spaces are lined by flattened cells and contain eosinophilic granular material and some macrophages. The interstitium contains a myxoid matrix (haematoxylin and eosin stain; original magnification, $\times 100$ ).

pleuritic in nature. A few studies have specifically looked at the findings of chest CT and magnetic resonance imaging scans, and have found that these lesions have characteristics consistent with benign nodules, but are otherwise nonspecific. $^{67}$ This is the first time a PET scan has been performed on a patient with alveolar adenoma and it was consistent with a benign process. Transbronchial biopsies, bronchial washings, and fine needle transcutaneous CT guided biopsies have been non-diagnostic in these cases. ${ }^{1-14}$ In most instances, these tumours have been surgically excised using a simple wedge resection of the lung. Frozen sections, when reported, have either been inconclusive or suspicious of alveolar adenoma, without being diagnostic. The growth potential of alveolar adenomas is unknown. Most have been stable over a short period of time, but at least one case showed $20 \%$ growth during an eight month follow up. ${ }^{3}$ In another, a "progressive enlargement" was noted over a period of one year. ${ }^{1}$

Macroscopic findings of previously reported cases have been consistent and similar to our own. ${ }^{1-14}$

In contrast, the histopathology is quite variable with the exception of being well demarcated and multicystic. 

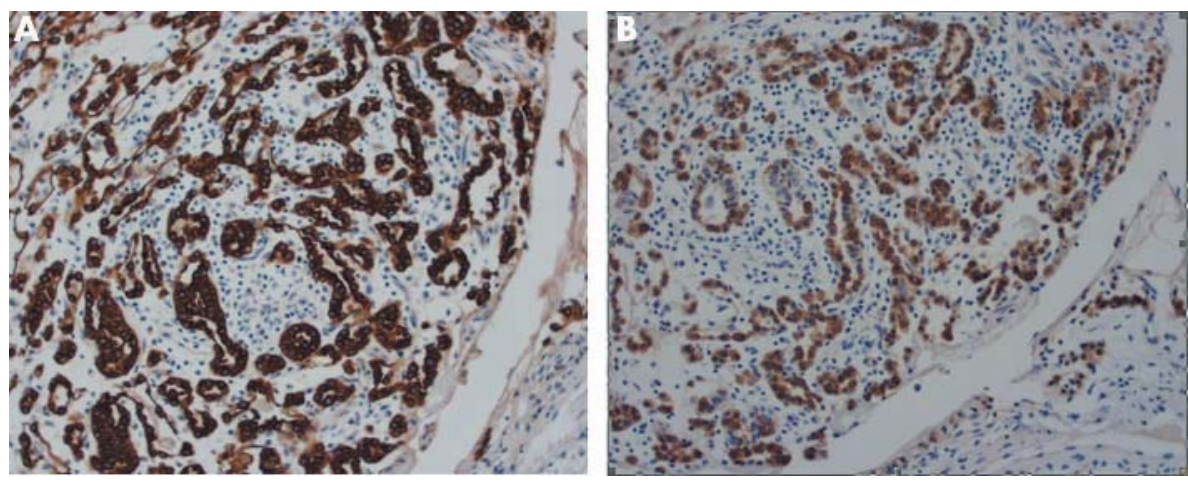

Figure 5 Immunohistochemical staining showing positivity for $(A)$ cytokeratin 7 (CK7) and (B) CK20 in the epithelial cells lining the cysts.

Microscopically, the cystic spaces dominate the picture, with the larger cysts usually concentrated in the middle of the tumour. The alveolar lumina usually contain few histiocytes, erythrocytes, and periodic acid Schiff positive granular material, as was seen in our case. The cysts are lined with a single layer of epithelial cells, with most of them being cuboidal or "hob nailed" in appearance. The cytoplasm is described as eosinophilic, finely vacuolated, or foamy. From the microscopic appearance and immunohistochemical studies, most authors agree that the epithelial component of this tumour is derived from type 2 pneumocytes..$^{1-14}$

The interstitial component varies from sparse to exuberant. It usually contains collagen fibrils and prominent spindle or oval shaped cells. Ultrastructurally, these cells resemble fibroblasts or modified smooth muscle cells. Most reported cases have shown mild to moderate numbers of interstitial lymphocytes, plasma cells, and eosinophils, occasionally in clusters. A well developed, fine capillary network traverses the interstitial mesenchyme, but no large blood cells or bronchioles are identified in these lesions. ${ }^{1-13}$

"From the microscopic appearance and immunohistochemical studies, most authors agree that the epithelial component of this tumour is derived from type 2 pneumocytes"

Immunohistochemical studies have consistently shown that the epithelial cells are positive for thyroid transcription factor 1 and almost all are CK positive. Although most reports do no specify the subgroup of cytokeratins tested, antibodies against AEl/AE3, CK1, CK7, CK18, and CK19 have been found to be positive in these tumours. ${ }^{2}{ }^{4}$ To the best of our knowledge, this is the first time that a CK20 positive alveolar adenoma has been reported. Köppl et al specifically tested for apoprotein B and C of human surfactant and found them to be positive, again confirming the theory that the epithelial cells are derived from type 2 pneumocytes. ${ }^{5}$ Immunohistochemical studies from several case reports have also verified that the interstitial cellular component of these tumours is made up of fibroblasts or fibroblast-like cells. ${ }^{2}$

Although most authors agree that alveolar adenomas are neoplastic in nature, some debate exists as to whether the epithelial or interstitial component of these tumours proliferates. In a recent study, Cavazza et al used microsatellite instability analysis to show that the stromal and epithelial components are genetically unrelated. ${ }^{14}$ This again confirms the apparent dual nature of these lesions. Morphologically, these tumours are very bland with rare mitoses. However, too few cases have been reported to verify their benign nature. Although rapid growth has occasionally been reported, no recurrence after resections has been seen. ${ }^{1-14}$ Roque et al

\section{Take home messages}

- We report a very rare case of alveolar adenoma of the lung, which was immunohistochemically distinct from previously reported cases in that it was positive for cytokeratin 20

- This is the first time that an alveolar adenoma has been evaluated using positron emission tomography

reported a non-balanced translocation demonstrated by fluorescence in situ hybridisation analysis on a single case of alveolar adenoma. This chromosomal abnormality is of unknown importance. ${ }^{11}$

In conclusion, we report a rare case of alveolar adenoma of the lung. Immunohistochemically, it differed from previous reports because it was positive for CK20. Clinically, this is the first time that an alveolar adenoma has been evaluated using a PET scan.

\section{Authors' affiliations}

A Halldorsson, S Dissanaike, Division of Cardiothoracic Surgery, Department of Surgery, Texas Tech University, Health Sciences Center, $36014^{\text {th }}$ Street, Lubbock, Texas 79430, USA

K S Kaye, Department of Pathology, Texas Tech University

Correspondence to: $\operatorname{Dr}$ A Halldorsson, Division of Cardiothoracic Surgery, Department of Surgery, Texas Tech University Health Sciences Center, 3601 4th Street, Lubbock, Texas 79430,USA; ari.halldorsson@ Huhsc.edu

Accepted for publication 11 March 2005

\section{REFERENCES}

1 Yousem SA, Hochholzer L. Alveolar adenoma. Hum Pathol 1986;17:1066-71.

2 Burke LM, Rush WI, Khoor A, et al. Alveolar adenoma: a histochemical, immunohistochemical, and ultrastructural analysis of 17 cases. Hum Pathol 1999;30:158-67.

3 Cakan A, Samacilar O, Nart D, et al. Alveolar adenoma: an unusual lung tumour. Interactive Cardiovascular and Thoracic Surgery 2003;2:345-7.

4 Böhm J, Fellbaum C, Bautz W, et al. Pulmonary nodule by an alveolar adenoma of the lung. Virchows Arch 1997;430:181-4.

5 Köppl H, Freudenberg N, Berwanger I, et al. Alveoläres Adenom der Lunge. Pathologe 1996;17:150-3.

6 Fujimoto K, Muller NL, Sadohara J, et al. Alveolar adenoma of the lung: computed tomography and magnetic resonance imaging findings. J Thorac Imaging 2002; 17:163-6.

7 Nussle K, Kolokythas O, Karhausen J, et al. Alveolar cell adenoma of the lung Rontgenpraxis 1997;50:29-30.

8 Oliveira P, Moura Nunes JF, Clode AL, et al. Alveolar adenoma of the lung: further characterization of this uncommon tumour. Virchows Arch 1996;429:101-8 
9 Haskovcova I, Povysil C, Pafko P. Alveolar adenoma of the lung (case report). Cesk Patol 1997;33:49-52.

10 Siebenmann RE, Odermatt B, Hegglin J, et al. Alveolar cell adenoma. A newly defined benign lung tumor. Pathologe 1990;1 1:48-54

11 Roque L, Oliveira P, Martins C, et al. A nonbalanced translocation (10;16) demonstrated by FISH analysis in a case of alveolar adenoma of the lung. Cancer Genet Cytogenet 1996;89:34-7.
12 Papla B, Malinowski E. Alveolar adenoma of the lung-a report of two cases. Pol J Pathol 2003;54: 147-52.

13 Menet E, Etchandy-Laclau K, Corbi P, et al. Alveolar adenoma: a rare peripheral pulmonary tumor. Ann Pathol 1999;19:325-8.

14 Cavazza A, Paci M, De Marco L, et al. Alveolar adenoma of the lung: a clinicopathologic, immunohistochemical and molecular study of an unusual case. Int J Surg Pathol 2004; 12:155-9.

\section{Clinical Evidence - Call for contributors}

Clinical Evidence is a regularly updated evidence-based journal available worldwide both as a paper version and on the internet. Clinical Evidence needs to recruit a number of new contributors. Contributors are healthcare professionals or epidemiologists with experience in evidence-based medicine and the ability to write in a concise and structured way.

Areas for which we are currently seeking authors:

- Antenatal monitoring

- Dietary supplementation and treatments in pregnancy

- Palliative care

- Prolonged pregnancy

We are also looking for authors for existing topics. For full details on what these chapters are please visit www.clinicalevidence.com/ceweb/contribute/index.jsp

However, we are always looking for others, so do not let this list discourage you.

Being a contributor involves:

- Selecting from a validated, screened search (performed by in-house Information Specialists) epidemiologically sound studies for inclusion.

- Documenting your decisions about which studies to include on an inclusion and exclusion form, which we keep on file.

- Writing the text to a highly structured template (about 1500-3000 words), using evidence from the final studies chosen, within 8-10 weeks of receiving the literature search.

- Working with Clinical Evidence editors to ensure that the final text meets epidemiological and style standards.

- Updating the text every 6 months using any new, sound evidence that becomes available. The Clinical Evidence in-house team will conduct the searches for contributors; your task is simply to filter out high quality studies and incorporate them in the existing text.

- To expand the topic to include a new question about once every 12-18 months.

If you would like to become a contributor for Clinical Evidence or require more information about what this involves please send your contact details and a copy of your CV, clearly stating the clinical area you are interested in, to CECommissioning@bmigroup.com.

\section{Call for peer reviewers}

Clinical Evidence also needs to recruit a number of new peer reviewers specifically with an interest in the clinical areas stated above, and also others related to general practice. Peer reviewers are healthcare professionals or epidemiologists with experience in evidence-based medicine. As a peer reviewer you would be asked for your views on the clinical relevance, validity, and accessibility of specific topics within the journal, and their usefulness to the intended audience (international generalists and healthcare professionals, possibly with limited statistical knowledge). Topics are usually 1500-3000 words in length and we would ask you to review between 2-5 topics per year. The peer review process takes place throughout the year, and out turnaround time for each review is ideally 10-14 days.

If you are interested in becoming a peer reviewer for Clinical Evidence, please complete the peer review questionnaire at www. clinicalevidence.com/ceweb/contribute/peerreviewer.jsp 